\title{
Nano Catalysis on Tailored Shape Supports: Au and Pd Nanoparticles Supported on MgO Nanocubes and ZnO Nanobelts
}

\author{
Garry Glaspell, Hassan M. A. Hassan ${ }^{\dagger}$, Ahmed Elzatahry ${ }^{\dagger \dagger}$, Lindsay Fuoco, \\ Nagi R. E. Radwan ${ }^{\dagger}$ and M. Samy El-Shall ${ }^{*}$ \\ Department of Chemistry, Virginia Commonwealth University \\ Richmond, Virginia 23284-2006
}

Supporting Information

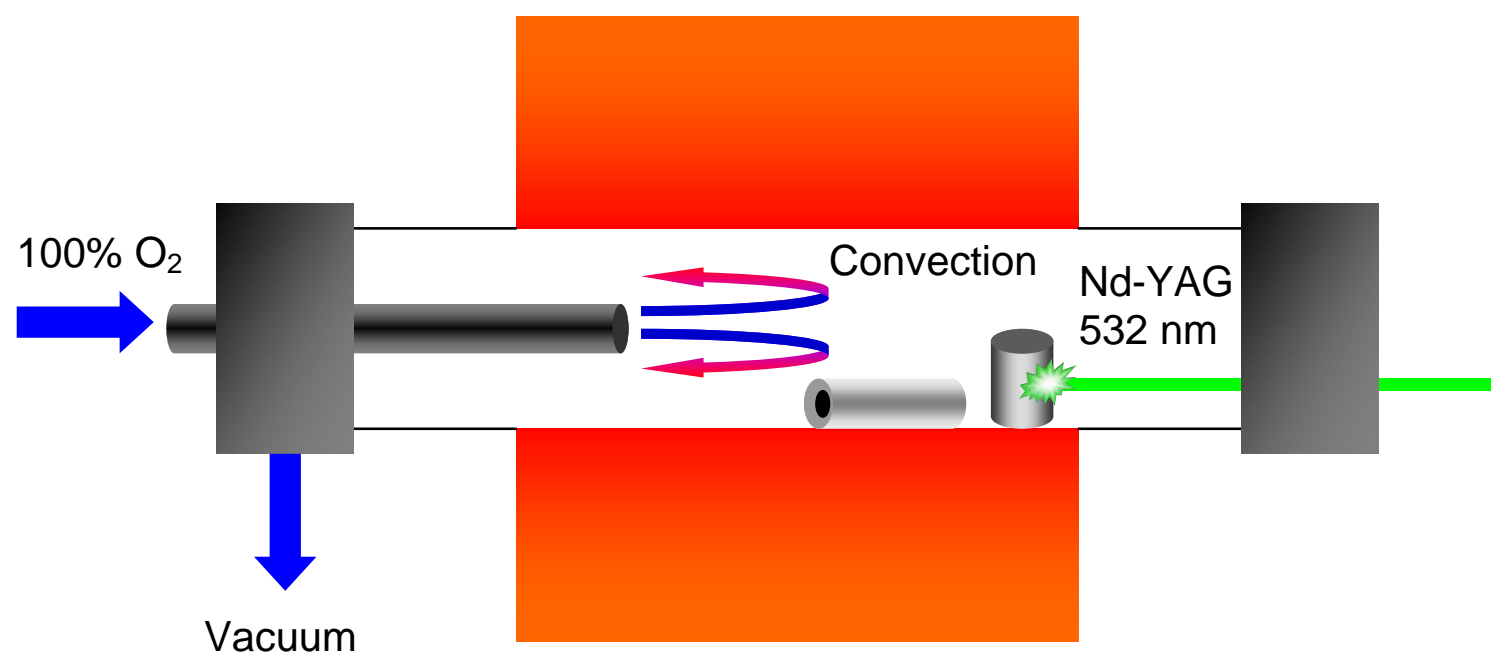

Experimental Setup for the synthesis of MgO belts terminated by transition metal tips ( $\mathrm{Fe}$, $\mathrm{Co}, \mathrm{Ni}$ ) using laser ablation of the transition metal targets and thermal evaporation of the $\mathrm{Mg}$ target in the presence of oxygen in a tube furnace. 